\title{
Design of a Mobile Game for Wireless Networks Planning Learning
}

\author{
Catalina Aranzazu-Suescun and Luis Felipe Zapata-Rivera \\ Florida Atlantic University, Boca Raton, United States \\ \{caranzazusue2014, lzapatariver2014\}@ fau.edu
}

\begin{abstract}
Game based learning has been a polemic topic during the last 10 years. There are different points of view between those who think that games only develop skills related with playing games such as: mental speed, reaction, connection between thoughts and movements and concentration. And those who think that additionally, games can improve the knowledge acquisition in a specific topic.

This research tries to show how both sides can be integrated to create gamming experiences that improve the student knowledge on wireless networks and make use of the powerful qualities of gamming to engage the students. This paper shows the implementation of an interactive game created using the latest technology for games design over mobile platforms. The game has been developed to improve the students' knowledge in the field of wireless networks planning. It allows students to solve simple problems of antennas distribution and progressively increase the level adding constraints and including new concepts in the design of the network. Basic elements of gamming were included such as scores, badges, characters, levels and a special tutorial mode that explain how to play the game but also mix the topic concepts.

The main goal of this game prototype is to create a game experience that can be played by any person in the basic level and with the acquisition of the knowledge the level of difficulty in the game will increase. Our hypothesis is: if a person masters this game he will also master the topic.
\end{abstract}

Keywords-Game-based learning, Mobile applications, Video games, Wireless networks planning.

\section{INTRODUCTION}

In the last 10 years, the concern about having new ways to teach the topics of STEM [1] and in general to engage the students and motive their active participation in the classrooms, had impulse the research in the game based learning field. These games have evolved from non-digital class games to digital games using computers in the classroom, and now, mobile online games where the students can be in any place, playing and learning.

Wireless network planning is a topic taught in the higher levels of electrical engineering program. Because its multiple variables of decision, it is hard to understand and dominate. However, it is possible to map it into a game due to its many configurable variables.

Digital Object Identifier(DOI):

http://dx.doi.org/10.18687/LACCEI2017.1.1.530

ISBN: 978-0-9993443-0-9

ISSN: $2414-6390$
Some of that variables are: location, type, height and orientation of the antennas, capacity of the base stations, transmission power, among others.

The article presents the design of a mobile game that has the goal of leverage the students learning in wireless network planning topic. The paper is organized as follows: section II presents the previous work in the game based learning; in section III, a description of the wireless network planning problem is presented. In section IV, the proposal of the game is shown; and in the section V, the conclusions and future work are stated.

\section{GAME - BASED LEARNING}

Game base learning is a methodology to use games to improve the knowledge in a specific topic. Normally those games are developed from scratch or are games modified to be used for learning purposes. These games could be used in the classroom, with or without using technology and sometimes are also called serious games. For this project, we focus our work in the digital games and more specifically in the mobile games.

The game-based learning focus on teaching educational content through games; so, the students can solve problems, make strategies, take decisions, learn and play. Game-based learning can help students to construct knowledge through trial and error and motivation. The games include strategies related to matching and challenging problem solving. Game based learning motivates students to learn intrinsically, because they can play in scenarios of real life where persistence is really important to achieve the goal of the game

$[2,3]$.

The new digital era where even the youngest people have access to internet and to all kind of digital content and even more to all kind of digital games, have impose a big challenge to teacher to seek new ways to engage students with the topics of their courses. Researchers have different opinions about the effectiveness of the game-based learning model. Many questions are now object of study: Can games improve the cognitive and mental skills of the students? or Can game based learning model improve the knowledge of the students?

[4]. 
The principle of game based learning is to engage the students to the game while enhance the learning experience. Seeing the popularity of some video games, companies have developed educational versions of these video games. Authors of [5] use MinecraftEdu to analyze the gamification and they have found a significant improvement on the students' innovation and motivation for the Social science field. Authors of [6] have developed their own game to help the students to mitigate their deficit in the mathematical skills. The work of [7], describes a change in educational games, on learning and assessment activities, making the student not only a player but a game maker. This is known as collaborative game making. Its importance lies in that students can make part of creating a game, where they can learn the class subject, inventing meaningful games to improve their knowledge. Games that are played in teams can improve the collaborative work as shown on [8,9]. In those works, it was found that people working in groups will have better retention and understanding of the concepts than those working alone. Teamwork allows students to work on critical thinking, analysis and synthesis, and thus achieve much higher performance than if they worked individually. Besides, working with people who have different thoughts, allows them to improve problem solving because they should discuss and make agreements between the parties.

Game based learning can improve several skills not only those related on the gamming related to thinking fast, reaction and concentration, but also the transferable skills, [10] which all professional needs to succeed in life $[11,12]$. The writing proficiency [13], motor skills [14], and teamwork, can help to improve the knowledge acquisition on some topic $[5,6,15,16]$.

\section{WIRELESS NETWORK PLANNING}

Planning a wireless network or generally any network requires solving an optimization problem that aims to achieve low installation costs and high levels of coverage to all users with good capacity and quality, network growth and reconfiguration. The variables to optimize are coverage, interference, capacity and resources, either minimize costs, number of channels used, possible tower locations, among others. Additionally, there is a set of decision variables, whose modification allow to find different solutions to the wireless planning problem. These decision variables are the location and height of the towers, number and type of antenna, orientation of the antenna, the number of channels, the number of radios, power transmission, among others [17].

Any solution to the planning problem is a sub-optimal solution, because, solving optimally this problem exceeds the actual time and computing power [18]. These planning problems can be established as NP-Complete problems, because of their multiple variables is almost impossible to find an optimal solution in polynomial time when the value of the variables is too large.

For this project, the problems that we use are the coverage and capacity. This is the formal definition of the problem:

Determine the optimal location in an area $\mathrm{T}$ of the minimum number of sites from a set of $\mathrm{N}$ sites available, to completely cover a set of $\mathrm{M}$ users and assign the required capacity, respecting the maximum capacity of each base station [17].

For simplicity of this prototype we fixed some parameters: transmission power, the height of the towers, orientation and type of antennas, one radio per antenna, the demanded capacity per user and a single frequency in all BS. The decision variables are the set of active sites among candidate sites and base station to which each user connects. Each base station deliveries the capacity required by the connected users, ensuring that the total demand of connected users is less than or equal to the total capacity of the base station. The figure 1 presents the scenario for the problem of coverage and capacity.

The total capacity of the base stations could be fixed as appears in the figure 1 or can be variable.

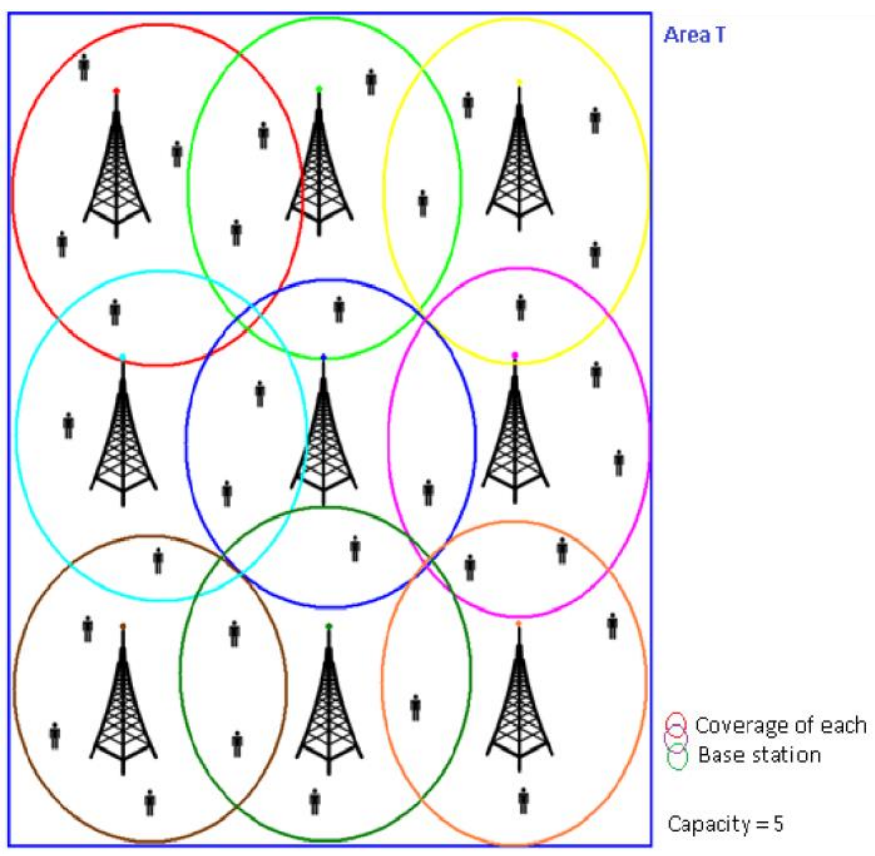

Fig 1. Scenario for coverage and capacity problem

\section{Proposal of THE GAME}

\section{A. Proposal description}

For the development of the game we integrate the improvement of the wireless network planning topic with the gamming engagement. This combination allows the possibility to create gamming experiences that leverage the student knowledge to a next level using the powerful qualities of gamming to engage the students.

Being in a technological age, it is necessary to potentiate and take advantage of information and communication technologies (ICT). There are several platforms to develop digital games such as: Unity [19], Unreal Engine 4 [20], GameMaker [21] among others. These platforms have different characteristics, such as development in $2 \mathrm{D}$ o $3 \mathrm{D}$, 
mobility, compatible with different operation systems such as: Windows, Linux, MacOS, iOS or Android.

The game was developed for a public that could have or not a previous knowledge on the wireless network planning topic. The idea is to teach some basic concepts of the wireless planning problem, but in an implicit way. Thus, the players after master the game could learn or improve more easily, fast and effective the wireless networks planning concepts. Also, the players can just play the game for entertaining purposes.

The game is based on a typical thief - cops game. The game takes place in the Manhattan streets. The story starts when a thief steals a big amount of money from a bank and a police patrol begin to haunt him. The thief tries to not be captured by the police driving around the streets, but in his attempt to escape, the bags of money drop out from his car. So, the thief will try to recover the bags but without being captured by the police. Then, the game starts with street covered by bags of money, a thief driving a red car and a police car.

The player will play the role of the police, so he will drive the police patrol to try to recover the bags of money before the thief. Each bag needs to be collected in some facilities that will be in some corners of the city. These are the basic rules:

- The principal goal of the game is to collect bags of money that the thief drops in a limited period of time.

- $\quad$ Each bag must be placed in some predefined facilities located around the city. The facilities refer to safes or to banks.

- The player car has a limited capacity to store the collected bags. The bags must be placed in facilities which are in 2 blocks around where they were collected.

- $\quad$ Each facility has a maximum capacity for bags that the player cannot overpass. If the player goes to a facility to place a bag and the facility is full, the player should go to another facility.

- $\quad$ For each bag that the thief recovers, the player score will decrease as a penalty.

- The game finalizes if: the limited time expires or if there are no more bags to collect in the field and the thief has been capture.

- The player wins if all the bags where collected from the street and the player collects more than the thief in the period time or in less time.

- If the player wins in less time than the given, the player will receive bonus points in its final score.

- If the time runs out and the player has collected more bags than the thief, the thief will surrender. But if there still time in the game and the player has more bags than the thief and there are no more bags in the street, the player can try to chase the thief to get some extra points.

The game has 3 levels, each one has more requirements and rules that resemble the coverage and capacity planning problem. The last level will be the one that has more similarity to the wireless planning problem. These are the detail descriptions of each level of the game:

- $\quad$ Level 1

The player needs to collect the bags before the thief. If the thief recovers more bags than the player when the time expires, the player will lose. The zone will have facilities every 2 blocks, 6 facilities in total and each facility has an unlimited capacity. The thief will drop out 20 bags on the streets.

\section{- $\quad$ Level 2}

Similarly to level one, the player need to collect the bags before the thief. The zone will have a facilities every 2 blocks, 6 facilities in total and but the facilities will have different capacities (a number between 2 and 5 bags). The thief will drop out 30 bags on the streets and will increase the speed of his car.

- Level 3

At the beginning of the game the player can see where are located the bags of money. With this knowledge, the player will choose where he wants to locate the facilities. The player has a maximum number of facilities to locate and some predefined places to locate them. For every facility that the player does not locate the final score will increase in a $10 \%$. The player will have an initial budget to place his facilities and each facility has a cost depending on its capacity. More capacity implies more cost. The capacity of each facility will be between 5 and 10. In this level, the thief will drop out 100 bags and will increase his speed. The game zone will be 4

times bigger than the area of the level 1 and 2.

\section{B. Mapping the game with the wireless network planning}

The table 1 shows the mapping of the assumptions and features of a simple wireless network planning problem, specifically, the coverage and the capacity problem with our game.

TABLE I

MaPPING THE REAL PROBLEM WITH THE GAME

\begin{tabular}{|l|l|}
\hline $\begin{array}{c}\text { Coverage and Capacity } \\
\text { problem assumptions }\end{array}$ & \multicolumn{1}{|c|}{ Game features } \\
\hline Area to cover & $\begin{array}{l}\text { Area where the thief drops } \\
\text { out the bags of money }\end{array}$ \\
\hline $\begin{array}{l}\text { Candidate sites to locate the } \\
\text { base stations }\end{array}$ & $\begin{array}{l}\text { Candidate sites for locate } \\
\text { the facilities to collect the } \\
\text { money }\end{array}$ \\
\hline $\begin{array}{l}\text { Capacity of the base } \\
\text { stations }\end{array}$ & Capacity of the facilities \\
\hline Demand of the users & Number of bags of money \\
\hline
\end{tabular}




\begin{tabular}{|l|l|}
\hline $\begin{array}{l}\text { Transmission range } \\
\text { of coverage }\end{array}$ & $\begin{array}{l}\text { The facilities are located } \\
\text { with a spacing of two } \\
\text { blocks }\end{array}$ \\
\hline $\begin{array}{l}\text { Objective of the problem: } \\
\text { Cover an area with base } \\
\text { stations and assign to each } \\
\text { user a base station to be } \\
\text { connected }\end{array}$ & $\begin{array}{l}\text { Level 1: Recover bags of } \\
\text { money before a thief } \\
\text { bringing them to some pre- } \\
\text { located facilities }\end{array}$ \\
\hline $\begin{array}{l}\text { Objective of the problem: } \\
\text { Cover an area with base } \\
\text { stations so all users have } \\
\text { assigned a base station and } \\
\text { every base station has a a } \\
\text { maximum number of users } \\
\text { that can connect }\end{array}$ & $\begin{array}{l}\text { Level 2: Recover bags of } \\
\text { bringing them to some } \\
\text { facilities with different } \\
\text { capacities }\end{array}$ \\
\hline $\begin{array}{l}\text { Objective of the problem: } \\
\text { Find the minimum number } \\
\text { of base stations with which } \\
\text { the entire area can be } \\
\text { covered and all users can } \\
\text { be connected to a base } \\
\text { station }\end{array}$ & $\begin{array}{l}\text { Level 3: Recover bags of } \\
\text { money before a thief } \\
\text { bringing them to some } \\
\text { facilities with different } \\
\text { capacities where the player } \\
\text { can choose the places to } \\
\text { put the facilities, the } \\
\text { capacity of each facility } \\
\text { with a given budget }\end{array}$ \\
\hline
\end{tabular}

It is important to notice that the problem used in the game has a lot of simplifications to allow the possibility to map it in an easy game. Then even public that do not have knowledge about the topic, can play it.

In level 3 of the game, the distribution of the bags in the streets resembled the distribution of people on the streets of Manhattan. Thus, there will be more bags in places where most people go. Now, with this feature and to have an extra link with the topic of the network planning problem, for level 3 of the game, we will run an approximated algorithm for the coverage with capacity problem, to identify possible suboptimal solutions to the given problem [17]. In this way, if the player finds a similar arrangement of the facilities, with capacities that are similar to the solution given by the algorithm, the player will receive an extra bonus in the game.

To access to this extra bonus, the user needs to choose the option in the menu and watch an introductorily video to the wireless network planning problem; feature that has been widely used in the current mobile games.

\section{Design of the prototype of the game}

The prototype of the game has been developed using Unity video games graphics engine (version 5.3.4 for Windows and free edition) and development framework. The sprites and assets have been retrieved from creative commons open content [22] and from Google maps satellite images
The controls are initially configured for desktop keyboard but Unity has the possibility to port the game to other platforms by doing minor changes such as changes the controls interface and the output resolution. In this way, it will be possible to have a complete digital experience: the mobility feature.

The architecture of the video games contains 4 layers: In the first layer are the user, defined as the students who are going to use the game, in this layer the system provides the player profile to be completed by the student. The second layer is the game interface, composed by the graphic elements such as: the sprites for each level, characters and additional elements. The third layer is the logic of the game, defined by the algorithms executed when the user triggers an event in the game. Those events are triggered by user input actions through the controller or because the user put his character in a situation that meets all the conditions defined to trigger the event (e.g. pass through any specific coordinate of the map in which a bag was dropped). The fourth layer is defined by the persistence of the data generated in the game such as score records, user current level etc. This layer need the support of a data base system.

The videogame logic was programed using $\mathrm{c}++$ language. A class model is presented in the figure 2.

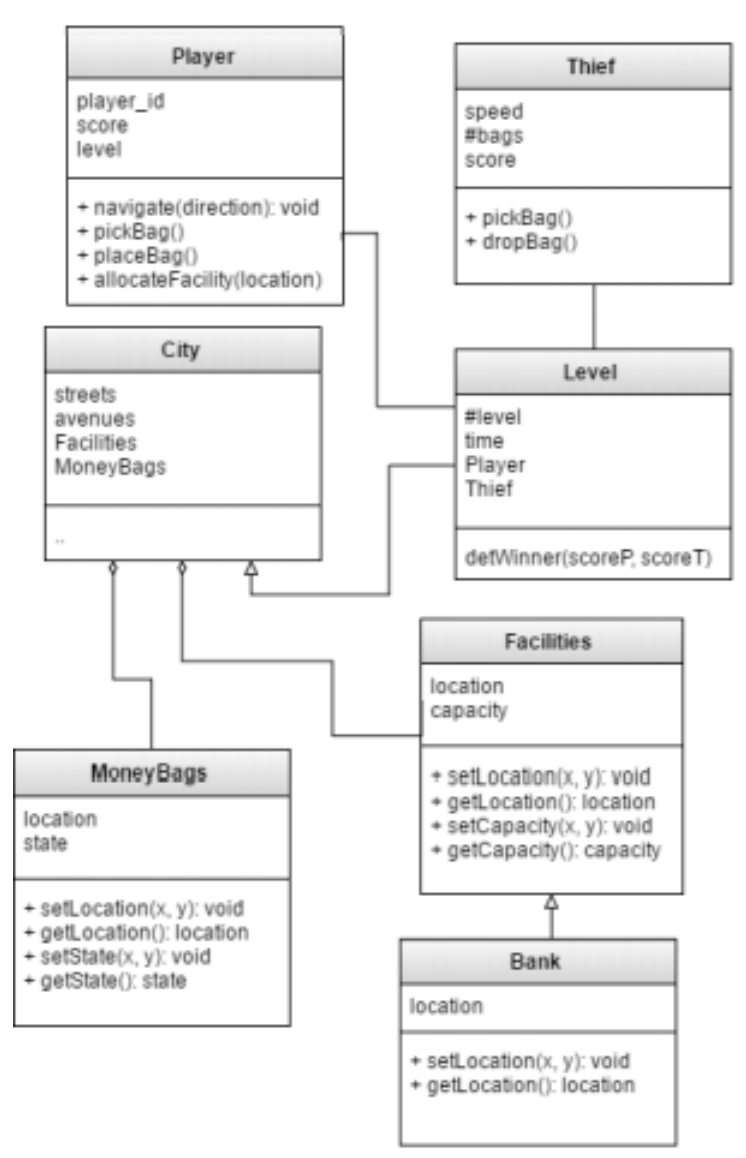

Fig 2. Scenario for coverage and capacity problem

$1^{\text {th }}$ LACCEI International Multi-Conference for Engineering, Education, and Technology: "Global Partnerships for Development and Engineering Education”, 19-21 July 2017, Boca Raton FL, United States. 


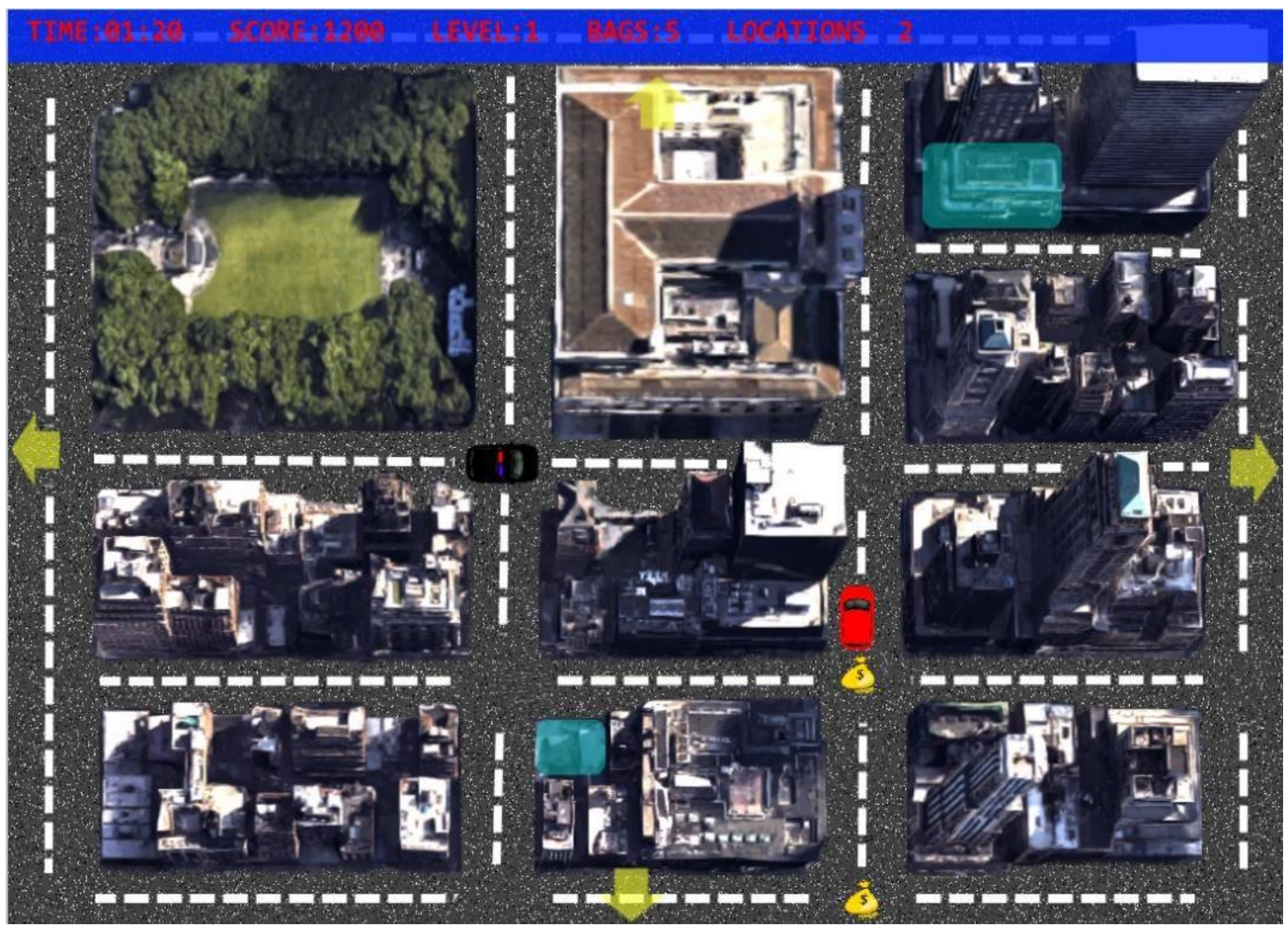

Fig 3. View of the level 1 of the game

The figure 3, presents an image of the level 1 of the game with a zoomed zone of the game. Some features of the game are:

- The yellow arrows indicate that the zone has been zoomed in. Then more streets can be driven in the game. However, the zone will be delimited in each level, this means that only some blocks will be part of the zone of the game, even in the level 3 that use the biggest zone.

- The game also has a tunnel effect similar to Pacman game [23], where the car can exit on the right and appear on the left part of the screen and vice versa.

- The game has a banner in the upper part of the screen where the player can see the progress of his game, with the elapsed time, the score due to the bags recovered, the level that is playing, the number of bags remaining and the number of locations or facilities in the zone.

- The facilities are identified with a transparent cyan rectangle.

- The thief drives the red car and the player drives the police car.

\section{CONCLUSIONS AND FUTURE WORK}

Some conclusions over this project are stated below:

Find the correct match between the two worlds, the topic concepts and the world of the game, is the way in how we can use the motivation generated for the games in favor of the learning.

One of the main ideas with this project is generate a general engaging video game, using a context for game completely different to the context of the topic, but keeping implicit the learning topics.

To simplify the complexity that the wireless network planning problem could have, we only work in the coverage and capacity problem, not the interference problem. We expect to include in the future work this last problem to increase the level of the game, and the complexity, so the students can learn more about the planning in wireless networks.

$1^{\text {th }}$ LACCEI International Multi-Conference for Engineering, Education, and Technology: "Global Partnerships for Development and Engineering Education”, 19-21 July 2017, Boca Raton FL, United States. 
As a future work we plan to make versions of the game with an extended story and with support of online multiplayer game, the possibilities can use different cities, bigger scenarios and multiplayer mode to also develop transferable skills such as team work.

Also, we plan to make a study to validate if the students that use the game improve their learning in the topic of wireless network planning concepts.

Finally, we want to use a validation engine of the game to probe if it is possible through playing the game give a solution to a wireless network planning problem.

\section{REFERENCES}

[1] STEM Education Coalition (Online): http://www.stemedcoalition.org/

[2] I. Chiang, R Shinh, E. Zhi-feng Liu and A. Jun-yen Lee, "Using game-based learning and interactive peer assessment to improve carreer goal and objectives for college students". International Conference on Technologies for ELearning and Digital Entertainment. Springer. 2011. DOI: 10.1007/978-3-64223456-9_91

[3] K. E. DiCerbo, "Game-Based Assessment of Persistence". Journal of Educational Technology \& Society, Vol 17, No 1, Jan 2014.

[4] A. S. Drigas, and M. A. Pappas, "On Line and Other Game-Based Learning for Mathematics". International Journal of Online Engineering (iJOE). Vol 11, No 4, July 2015. DOI: 10.3991/ijoe.v11i4.4742

[5] R. Cozar-Gutierrez and J. M. Saez-Lopez, "Game-based learning and gamification in initial teacher training in the social sciences: an experiment with MinecraftEdu". International Journal of Educational Technology in Higher Education. Vol 13, No 2, 2016. DOI: 10.1186/s41239-016-0003-4

[6] S. Y. Syed Hussain, W. H. Tan and M. Zaffwan Idris, "Digital Game-Based Learning for Remedial Mathematics Students: A New Teaching and Learning Approach in Malaysia". International Journal of Multimedia and Ubiquitous Engineering. 2014. Vol 12. Jun, 2016. DOI: 10.1186/s41239-016-0003-4.

[7] K. Osman and N. A. Bakar, 2013. "Teachers and Students as Game Designers: Designing Games for Classroom Integration”. New Pedagogical Approaches in Game Enhanced Learning: Curriculum Integration. Apr 2013.

[8] S. Bermingham, N. Charlier, F. Dagnino, J. Duggan,J. Earp, K. Kiili, E. Luts, L. van der Stock, and N. Whitton, 2013, "Approaches to Collaborative GameMaking for Fostering 21st Century Skills". The 7th European Conference on Game Based Learning. Portugal, Oct 2013.

[9] A. A. Gokhale, "Collaborative Learning Enhances Critical Thinking". Journal of Technology Education. Volume 7, Number 1 Fall 1995 (Online): http://scholar.lib.vt.edu/ejournals/JTE/v7n1/gokhale.jte-v7n1.html

[10] L. F. Zapata-Rivera and C. Aranzazu-Suescun, "Game-Based Assessment for Radiofrequency Circuits courses in Engineering". Frontiers in Education. El paso, TX - USA. Oct 2015. DOI: 10.1109/FIE.2015.7344108

[11] M. binkley, O. erstad, J. Herman, S. Raizen, M. Ripley and M. Rumble, 2010. "Draft white paper 1: Defining 21st century skills". Learning and Technology Forum. London.

[12] A. P. Carnevale, 2013. "21st Century Competencies for College Readiness". Skills for career Success in the 21ST Century (Online): www.NCDA.org.

[13] H. O’Donnell, “Games-Based Learning as an Interdisciplinary Approach to Literacy across Curriculum for Excellence". Press Start Gamesbased Interdisciplinary Learning in CfE. 2015.

[14] H. S. Hsiao and J. C. Chen, "Using a gesture interactive game-based learning approach to improve preschool children's learning performance and motor skills". Computers \& Education. Vol 95, Apr 2016. DOI: 10.1016/j.compedu.2016.01.005

[15] D. C. Rotaru, B. Fernandez-Manjon, A. Katri and R. H Tambouret, "Design and Development of a Serious Game for Medical Training in Cytopathology". The 6th International Conference on Digital Health Conference. Montréal, Québec - CA. Apr, 2016. DOI: $10.1145 / 2896338.2897731$.
[16] Y. K. Juan and T. W. Chao, "Game-Based Learning for Green Building Education”. Sustainability 2015. Vol 7, No. 5. May 2015. DOI: $10.3390 /$ su7055592.

[17] C. Aranzazu-Suescun and R. Hincapie-Reyes, "Solution to the wireless network planning problem through sub-optimal algorithms". Master thesis. Pontificia Bolivariana University. Medellin - Colombia 2011.

[18] T. H. Cormen, C. E. Leiserson, R. L. Rivest and C. Stein, "Introduction to Algorithms". Third edition. MIT Editorial. Unite states. 2009.

[19] Unity-Game engine, (Online): https://unity3d.com/

[20] Yo Yo Games - Game Maker, (Online): http://www.yoyogames.com/gamemaker

[21] Unreal Engine, (Online): https://www.unrealengine.com/

[22] CC Creative Commons, (Online): https://search.creativecommons.org/

[23] Nintendo Pacman, (Online): http://nintendo.wikia.com/wiki/PacMan_(video_game)

$15^{\text {th }}$ LACCEI International Multi-Conference for Engineering, Education, and Technology: "Global Partnerships for Development and Engineering Education”, 19-21 July 2017, Boca Raton FL, United States. 